\title{
A Framework to Leverage and Mature Learning Ecosystems
}

\author{
https://doi.org/10.3991/ijet.v15i05.11898
}

William Derek Redmond ${ }^{\varpi}{ }^{\circledR}$, Leah P. Macfadyen

The University of British Columbia, Vancouver, Canada

redmondweoutlook.com

\begin{abstract}
With the average shelf life of an employee's skills at less than five years, it is imperative that organizations support their employees in staying current in new and emerging skills and in learning how to learn. Learning management systems, once seen as a one-size-fits all learning solution, have not effectively kept pace with wider technology development, and the needs and expectations of workplace learning. Moreover, organizations tend to have too narrow a view when considering the elements that affect learning at their organization. An ecological and holistic approach is needed to improve learning environments and to future-proof these environments for new developments in education and technology. This paper explores the existing literature and frameworks for learning ecosystems and proposes a new learning ecosystem framework that consists of seven key elements: (1) technology and data architecture, (2) governance, (3) analytics, (4) semantic ePortfolios, (5) intrinsic and extrinsic motivators, (6) social learning and engagement, and (7) personalization.
\end{abstract}

Keywords - Learning ecosystem, learning analytics, education technology, learning environment, learning management system

\section{Introduction}

Learning is part of a human's life. With the average shelf life of an employee's skills at less than five years, it is imperative that organizations support their employees in staying current in new and emerging skills and in learning how to learn $[1,2]$. Considering this reality against a backdrop of globalization, rapid technological development, and redefinition of our social, cultural, and organizational systems, it is clear that it is time to rethink how learning is achieved [3].

Learning management systems (LMSs) were once seen as a one-size-fits-all learning solution and have been widely adopted by schools and organizations. However, it is clear that LMSs are more successful in facilitating the administration of learning rather than facilitating the learning process $[4,5,6]$. The course- and instructorcentric design of LMSs often do not support modern pedagogies, which may not be effective or possible in the traditional LMS without expensive upgrades or integrations $[5,4]$. Additionally, the rapid development of other technologies and poor interoperability between LMSs and other learning systems have meant that some LMS 
companies have struggled to keep up [7]. Limitations of the current state are described in Table $1[7,3,4]$.

Table 1. Limitations with the current state

\begin{tabular}{|l|l|}
\hline \multicolumn{1}{|c|}{ Limitation } & \multicolumn{1}{c|}{ Description } \\
\hline $\begin{array}{l}\text { Rapid technology } \\
\text { development }\end{array}$ & $\begin{array}{l}\text { Technology is developing so rapidly that organizations need to continuously } \\
\text { upgrade their infrastructure. It creates an environment where there is a need to } \\
\text { purchase new learning applications to supplement the affordances of current } \\
\text { systems. }\end{array}$ \\
\hline Lack of interoperability & $\begin{array}{l}\text { Many learning systems attempt to lock you in to their products, which creates a } \\
\text { lack of flexibility for learners and instructors and limits the ability to integrate } \\
\text { new tools. It can be extremely expensive to develop integrations between two } \\
\text { learning systems. This lack of interoperability creates an environment where } \\
\text { organizations have multiple siloed systems which operate independently from one } \\
\text { another. }\end{array}$ \\
\hline Poor learning data & $\begin{array}{l}\text { Most education data captured is spotty, meaningless, and is recorded in discon- } \\
\text { nected and siloed systems which speak different languages. This creates an envi- } \\
\text { ronment where learning data cannot be used effectively to improve content or } \\
\text { learning environments and where it is difficult to correlate data from multiple } \\
\text { systems and/or in class activities. Additionally, informal learning data is often not } \\
\text { considered and not captured. }\end{array}$ \\
\hline Lack of cohesion & $\begin{array}{l}\text { Most learning experiences are disconnected from one another and lack cohesion. } \\
\text { The amalgamation of lifelong and institutional learning is difficult when access to } \\
\text { learning content and an individual's learning data is no longer accessible if they } \\
\text { leave a specific school or organization. }\end{array}$ \\
\hline Lack of personalization & $\begin{array}{l}\text { Learners have little to no control over the environments in which they are en- } \\
\text { gaged. This can include not being able to control the pace of their learning, sys- } \\
\text { tems not being responsive to the needs of the specific learner, not being able to } \\
\text { choose what content they engage with, and not being able to access a system with } \\
\text { their own personal device. Additionally, it is typically the needs of the organiza- } \\
\text { tion, not the needs of the learner that informs the design and requirements of a } \\
\text { learning system. }\end{array}$ \\
\hline
\end{tabular}

To address these challenges there is a need to think about the learning environment from a different perspective. To ensure life-long learning so learners continue to gain new knowledge and skills, learning environments must be flexible and personalized to the needs of the learner [5]. An ecological and holistic approach is needed to improve learning environments and to future-proof these environments for new developments in education and technology $[5,8,9,2,4,10,7,6]$.

This paper will describe the ecological and holistic approach of a learning ecosystem and how organizations can tap into it to optimize their learning environment. The following sections will define and describe a learning ecosystem and will propose and describe a new learning ecosystem framework. While this paper is situated in a corporate learning context, the new learning ecosystem framework is also relevant for K-12 and higher education. 


\section{$2 \quad$ Learning Ecosystems}

The concept behind a learning ecosystem stems from the biological ecosystem, which is defined as a "complex of living organisms, their physical environment and all their interrelationships in a particular unit of space" [11]. A biological ecosystem consists of biotic (living) and abiotic (non-living) units and all the interconnected relationships between them within specified physical boundaries [5]. Ref. [5] offers a simplified view of the learning ecosystem as seen in Figure 1.

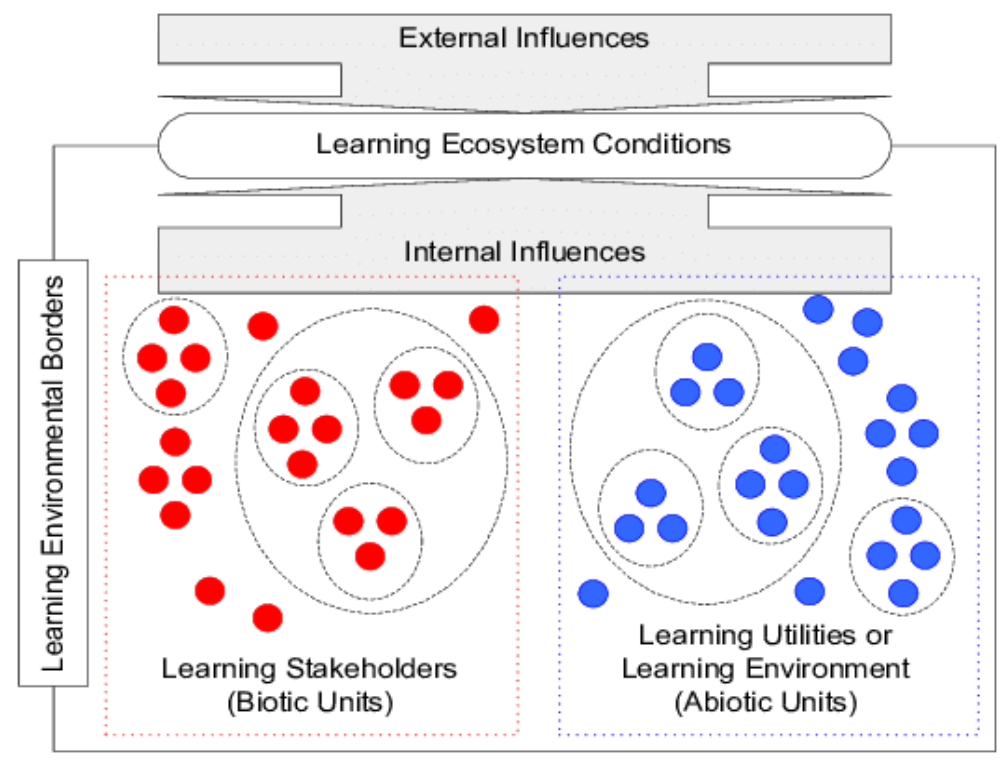

Fig. 1. Simplified representation of a learning ecosystem [5]

The biotic units (learning stakeholders) consist of the living elements in an ecosystem. This can include teachers, content developers, instructional designers, learners, etc. The abiotic unit (learning utilities or learning environment), are the non-living elements. This can include learning content, learning management systems, mobile apps, websites, analytics systems, etc. The biotic and abiotic units together create the learning environment. The borders of the learning environment are influenced by internal and external factors such as organizational or governmental policies and strategies, learning culture, the evolution of knowledge in society, cultural and sociological aspects, etc. [5]. These elements together create the learning ecosystem.

A learning ecosystem can be defined as "A system of people, content, technology, culture, and strategy, existing both within and outside of an organization, all of which has an impact on both the formal and informal learning that goes on in that organization" [12]. Every organization has a learning ecosystem in some state of maturity. Take the example of an organization that simply has a learning management system. In this case, the abiotic units of the ecosystem might consist of the LMS, the learning 
content housed on the LMS, learning content delivered in person, the human resource information system (employee profiles), and active directory (authentication system for logging in). The biotic units might consist of the subject matter experts, the instructional designers, the content developers, and the learners who engage with the content. Internal influences might include the education policies, strategies, and learning culture of the organization. External influences to the organization might include what is being taught by colleges and universities that their current and new staff are engaged with, videos on YouTube staff are watching, articles staff are reading, staff who are engaging with champions and other staff on social media, who may be from within and from other organizations, and government legislation, strategies and budgets. The ecosystem perspective is interested in the relationships and interactions between the biotic and abiotic units, and the internal and external influences that all affect the ecosystem [5]. It is interested in the natural and spontaneous clusters and groups that interact with one another (visualized as the circles in Figure 1) and it is interested in how the conditions of the learning ecosystem influence the behaviour of the biotic and abiotic units [5]. An understanding and recognition of these relationships puts an organization at a strategic advantage - allowing them to take informed action to influence the overall ecosystem to better meet their desired outcomes and to better support the learning process.

The generic overview of a learning ecosystem described in Ref. [5], does not however address how organizations can tap into and mature the learning ecosystem that already exists in their organization. A framework that considers details of the entire ecology of a learning ecosystem is needed to guide organizations in maturing their learning ecosystem. The next section of this paper reviews existing literature on learning ecosystem frameworks and identifies gaps that exist. These frameworks are then combined into a new learning ecosystem framework that fills these gaps.

\section{$3 \quad$ Learning Ecosystem Framework 2.0 (LEF 2.0)}

Ref. [9] reviews several ecosystem-based learning models and emphasizes the need for a framework which combines and extends these models. Since publication of that paper, new frameworks have appeared that attempt to do accomplish this. Ref. [4] proposes a model with five domains that should be considered to fully realize a Next Generation Digital Learning Environment (NGDLE). These domains include:

1) Interoperability and integration

2) Personalization

3) Analytics, advising, and learning assessment

4) Collaboration

5) Accessibility and universal design

Ref. [6] proposes an ecosystem that pivots around:

1) A framework architecture that supports learning service-based ecosystems

2) Learning analytics for educational decision making 
3) Adaptive knowledge systems

4) Gamification of learning processes

5) Semantic portfolios to collect evidence of learning

These proposed frameworks combine many of the elements discussed in the Ref. [9] review, but neither considers internal and external influences on the learning ecosystem as discussed in Ref. [5]. The framework proposed in Ref. [6] lacks consideration of the networks formed between biotic units in the ecosystem. Other frameworks such as Ref. [13]'s e-Learning theoretical framework and Ref. [14]'s learning ecosystem to support flipped classrooms, are useful in their local context, but are too narrow in focus to be widely utilized. While considerable progress had been made in developing a learning ecosystem framework as visualized in Figure 1, work is still needed to actualize a framework that empowers organizations to take action to shape their learning ecosystem to meet their desired outcomes and to better support the learning process.

The new learning ecosystem framework, called the Learning Ecosystem Framework 2.0 (LEF 2.0), described in this paper builds on older models described in the learning ecosystem literature and goes beyond existing work by considering research and best practices within each framework element. The LEF 2.0 is offered as a guide to help organizations take control of, utilize, and improve their learning ecosystem, while being flexible and adaptive to the needs of the learner and the organization. The LEF 2.0 should be worked towards in stages and is intended as a starting point for planning. Each element offers a possible step towards maturation of an organization's learning ecosystem, but the framework need not be implemented in its entirety. Instead, organizations should draw from it strategically, to allow customization of their ecosystem to the needs of the learners and of the organization. This newly proposed LEF 2.0 consists of seven key elements:

1) Technology and data architecture

2) Governance

3) Analytics

4) Semantic ePortfolios

5) Intrinsic and extrinsic motivators

6) Social learning and engagement

7) Personalization

\section{Technology and Data Architecture}

The technology and data architecture is the most important element as it forms the foundation of the learning ecosystem. As the authors of Ref. [15] remind us, "in any system, the foundation on which a learning ecosystem is built determines the capabilities and the extensibility of the learning ecosystem" (p. 1). If this element is not at the forefront of design considerations, future issues are likely to arise as the scope of use and the demands on the learning ecosystem increase. The potential for a learning ecosystem to provide meaningful learning experiences, scale to meet future data 
needs, and support future technological and pedagogical design developments will be severely hindered by poor technology and data architecture [15].

\subsection{Technology architecture}

The technology architecture comprises all the technology required to run and manage a learning ecosystem. This may include LMSs, apps, websites, student information systems, authentication systems, competency database, data stores, data analytics systems, eLearning authoring tools, etc. To maximize the affordances of the technology architecture, integration and interoperability, the learning experience, and organizational needs should be considered.

Integration and interoperability: An LMS is not a one-size-fits-all solution. To support new pedagogies and new technologies, and to ensure scalability, the LMS must be supplemented. Much of the literature speaks to the need for easy integration and interoperability of all technology within a learning ecosystem $[4,7,6,10,3,16]$. Ref. [6] argues that the integration of these platforms requires "communication protocols, interfaces, and data and resource description standards" (p. 469) that enable the flow of data between them. Ref. [4] outlines four key dimensions for interoperability within their NGDLE model:

1) All systems must be able to accept and exchange learning content in common formats

2) Integration must be easy enough for users to quickly add tools to their environment

3) The learning environment must be the key source of learning data

4) Use of interoperability standards that are compatible with other common standards

The IMS Global Learning Consortium developed the learning tools interoperability (LTI) standard in 2013 as an open specification for enabling plug-and-play integration of learning technologies [17]. LTI offers a way to easily and securely connect learning applications with learning platforms [18]. The latest version, called LTI Advantage (LTI version 1.3), brings several upgrades and is shown in Figure 2. 


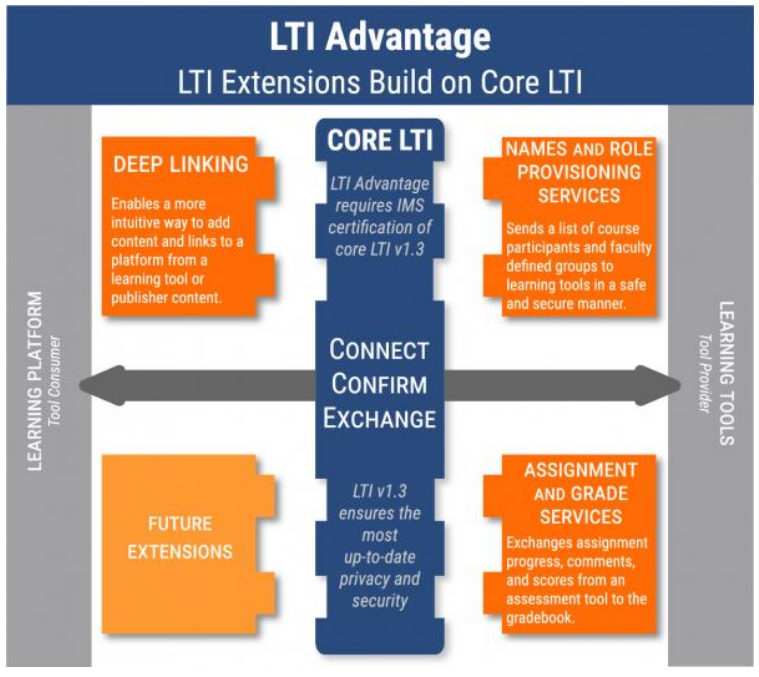

Fig. 2. LTI Advantage [18]

Typically, organizations have a core learning platform, such as an LMS or similar platform, which all learning tools are connected via LTI. The LTI core constructs a secure connection, confirms the tool's authenticity, and authenticates the user via OAuth2. This exchange allows for learning data to be passed between the tools [18].

The Advanced Distributed Learning Initiative (ADL) is conducting similar work to the IMS Global Learning Consortium and LTI. The ADL was created in 1999 by a United States Presidential order to aid the Department of Defense in crafting "a vision for tailored, anytime, anywhere learning, and provide research and end-user facilitation to help reach that vision" [10, p. 2]. The ADL has lead development of specifications such as the Sharable Content Object Reference Model (SCORM) and the Experience API (xAPI). Recently, the ADL developed the Total Learning Architecture (TLA), which specifies data models, development patterns, and interfaces for creating interoperability between learning systems [10,3]. The TLA offers a modular and scalable ecosystem that enables a diverse set of learning systems, each with their own niche in support of individual learning needs, to communicate and collaborate with one another, and share learning content and resources between them [10]. Through greater interoperability, the freeing of content from specific learning systems, and recommender algorithms, the TLA hopes to support a learner's immediate needs and support their professional development across their entire career [10, 19].

There appear to be similarities in the methods and specifications that TLA and LTI employ to facilitate interoperability and learner support. This is likely to cause confusion about which specification an organization should adopt, as they seek to mature their learning ecosystem. In 2016, the IMS Global Learning Consortium and ADL began talks to compare their specifications and discuss whether there was opportunity for collaboration or integration of specifications [20]. Several recommendations were made during this meeting; however, progress to date is unclear. 
The learning experience: The needs of the learner and a learning-centered model should be an important factor when planning the technology architecture of a learning ecosystem [7, 4]. 'Learning experience design' is an amalgamation of user experience design, instructional design, and design thinking [21]. When designing the learning experience, how learning occurs must be considered [22, 23] and the technology architecture must be developed to support this process across a learner's entire career. From signing up for an account through to engaging with the learning ecosystem for an entire career, the technology should support the learner in achieving their learning goals and keep them in their zone of proximal development [24]. Many elements in the LEF 2.0 affect and support the learning experience, making it critical to consider the learning experience when discussing the elements in the framework.

Organizational needs: There is a gap in existing literature on learning ecosystems and the design of the technology architecture. Existing literature on development of learning ecosystems considers learner needs, and the learner experience, but consideration of the organization's needs (e.g. existing reporting mechanisms, system integrations, security requirements, electronic devices available at the organization, and human and monetary resources available to support the learning ecosystem) is missing. Certainly, an exclusive focus on organizational needs as the driver of learning ecosystem design would be problematic - for example, Ref. [25] highlights a real-world case study in which the organization's technical requirements, rather than evidence of actual student usage patterns in the LMS, dominated the process of selecting a new LMS. However, the absence of literature on approaches to balancing organizational needs with learner needs in learning ecosystems is problematic, given the importance of an ecological perspective. Organizational needs, and the capacity for a learning ecosystem to support these needs, affect the entire ecosystem. For example, the potential to collect and make use of more and more useful educational data may facilitate improved institutional reporting and might usefully inform future education policies, pedagogies, and strategies. An opportunity for future research exists here, specifically the different ways in which a matured learning ecosystem can support the needs of an organization, as well as the needs of its learners.

\subsection{Data architecture}

The data architecture is the most important design consideration in developing a learning ecosystem [15]. The common phrase "garbage in, garbage out" is particularly true here. The quality of the data architecture will determine how effectively data can move around and be utilized in an ecosystem. It affects how elements 3-7 of the LEF 2.0 can be implemented and utilized to their full potential. The data architecture includes:

1) Data sources

2) Data stores

3) Data models

4) Data logistics

5) Data processors [15]. 
Data sources: Data sources may include a wide range of tools, sites or systems where learning data is being generated [15]. This may include LMSs, data from generated from within learning content (e.g. SCORM or xAPI), learning experience platforms (LXP), apps, websites, simulations, serious games, IoT devices, social media sites, student information systems, or human resources information systems (HRIS).

Data stores: Learning data is stored in data stores [15]. Decentralization of learning systems creates challenges for the capturing and use of educational data [26], and cloud-based data stores appear to offer better interoperability [7, 26, 4, 27]. Ideally, a central repository of all learning data would exist, however this is dependent on the data models used. For example, in an Experience API (xAPI) powered ecosystem, an LRS could act as the central repository of data where other systems in the learning ecosystem can POST and GET data from. Should multiple data models be used, a data lake may be required for centralization (A data lake is a centralized repository that allows for the large-scale storage of structured and unstructured data which are stored until needed [28]).

Data models: Data models include standardized data definitions and vocabularies, data transport mechanisms and methods of storing and validating data [15]. This requires implementing standardized data methods and languages throughout the learning ecosystem. (A simple example: "learning system A" may state that "John Smith watched the learning analytics best practices video for 5 minutes" while "learning system B" may state that "user 4839 engaged with the learning analytics best practices video for 300 seconds". Implementation of standard data methods and languages avoids such problems.

xAPI and Caliper are two learning data models that have emerged recently. xAPI, developed by the ADL, is a data transport and storage mechanism [29]. It is an open specification that offers a flexible and customizable structure which makes it possible to collect learning data from a wide range of learning experiences across multiple learning systems [30]. eLearning developers can create custom xAPI statements within eLearning authoring tools or directly in HTML using JavaScript triggers. The flexibility offered by xAPI allows the developer to capture almost any learner engagement data needed. XAPI also includes XAPI profiles, such as CMI5, that provide additional structure and rules for use [29]. Caliper, developed by the IMS Global Learning Consortium, is similar to XAPI in that it collects learning data from multiple digital resources to provide more insightful learning analytics [31]. The authors of Ref. [29] conducted a thorough review of XAPI and Caliper, noting their similarities and highlighted four main differences. The differences include: (1) Licensing - Caliper has a closed license, while XAPI has an open Apache 2 license, (2) Governance - Caliper is governed by the IMS consortium, while XAPI is governed by the Data Interoperability Standards Consortium (DISC), although the xAPI specification is open source, (3) Approaches to development of core vocabularies and profiles - Caliper offers standardized profiles, while XAPI is open source, allowing the community to develop the vocabulary and offer profiles, and (4) Security and data protection - Caliper utilizes an API key, HTTPs/TLS 1.3 and JSON-LD while XAPI uses basic HTTP authentication, oAuth 1.0, and JSON respectively [20, 29]. Given the similarities between the two models, the IMS Global Learning Consortium and ADL have initiated consulta- 
tions with the goal of moving towards an amalgamation of the two data models [31]. It remains to be seen what the outcome of this work will be.

Data logistics: Data logistics provide the methods for data to flow between systems and can include services such as identity, integration, and processing [15]. Streaming architectures such as Apache Kafka or AWS Kinesis provide data management and connections between data processors, allowing for real-time collection, processing, and sending of data and removing the need for sending batch data updates $[15,32]$. Access to and utilization of real-time data could permit development of more useful dashboards and more effective adaptive knowledge systems (part of element seven of the LEF 2.0).

Data processors: Data processors use and make meaning from the data provided by the data logistics methods. They transform raw data into a format usable by humans or other systems [33]. These can include recommendation systems, competency systems, learning analytics systems [15], and human-readable formats such as reports or push notifications. Data processors are critical for adaptive knowledge systems (part of element seven of the LEF 2.0).

\section{Governance}

For a learning ecosystem to run effectively, there must be structures in place to manage the internal influences and react to external influences (see Figure 1), make decisions based on learning data and analytics, and guide the focus and direction of the ecosystem in support of the organization's goals. Governance provides an avenue to do this by focusing on high-level work, including developing and managing cohesive policies, processes, and decisions, and achieving alignment between organizational goals and how the ecosystem supports these goals [8, 34]. Ref. [34] offers a summary of eLearning governance processes in the literature which has been adapted for a learning ecosystem as shown in Table 2.

Table 2. Learning ecosystem governance

\begin{tabular}{|l|l|}
\hline \multicolumn{1}{|c|}{ Element } & \multicolumn{1}{c|}{ Necessary steps } \\
\hline Roles \& responsibilities & $\begin{array}{l}\text { Define roles and responsibilities and organizational structure for govern- } \\
\text { ance members [8]. This may include [8, 15]: } \\
\text { a chief learning officer } \\
\text { a chief information officers } \\
\text { project manager } \\
\text { strategy committee } \\
\text { steering committee(s) }\end{array}$ \\
\hline Learning strategy & $\begin{array}{l}\text { Develop a learning strategy in support of organizational goals and learner } \\
\text { needs [8, 7]. This may include a competency-based learning strategy } \\
\text { where learning content, assessments, and evaluations are developed } \\
\text { around supporting desired competencies in the organization [4, 35]. Learn- } \\
\text { ing strategy must also include considerations of factors external to the } \\
\text { learning ecosystem, such as government policies and funding, which may } \\
\text { affect the ecology. }\end{array}$ \\
\hline
\end{tabular}




\begin{tabular}{|l|l|}
\hline Investment approval & $\begin{array}{l}\text { Define strategies and processes to ensure that investments in the ecosys- } \\
\text { tem generate significant returns and value for the organization [34]. }\end{array}$ \\
\hline Architecture & $\begin{array}{l}\text { Develop processes to determine architectural requirements needed for } \\
\text { continuously supporting the learning ecosystem [34]. }\end{array}$ \\
\hline $\begin{array}{l}\text { Data ethics, privacy and } \\
\text { security }\end{array}$ & $\begin{array}{l}\text { Develop policies and strategies around data ethics, privacy, and security } \\
\text { [36, 37]. }\end{array}$ \\
\hline Development & $\begin{array}{l}\text { Develop processes to create and maintain learning resources [34]. This } \\
\text { may include [8]: } \\
\text { instructional design process } \\
\text { learning development process } \\
\text { content review process } \\
\text { style guides }\end{array}$ \\
\hline Service level agreements & $\begin{array}{l}\text { "Develop processes to list available services, alternative quality levels, and } \\
\text { related costs" [34, p.531]. }\end{array}$ \\
\hline $\begin{array}{l}\text { Evaluation and assess- } \\
\text { ment }\end{array}$ & $\begin{array}{l}\text { Determine accounting mechanisms for allocating central learning ecosys- } \\
\text { tem costs to business units [34]. } \\
\text { updating learning content [34]. }\end{array}$ \\
\hline
\end{tabular}

\section{Analytics}

The Internet, and more recently the explosion of mobile devices, wearable technology, and IoT (internet of things) devices, have vastly increased the volume of user activity data that can be collected in many contexts. We have come to rely on these devices as part of our everyday lives - as a source of information, access to entertainment, communication, shopping, banking, and work [38]. The vast amounts of data now commonly captured is often referred to as Big Data. Analytics - the practice of using data to inform decision making [39] - has become an integral feature of marketing and business intelligence. Analytics are being used to focus product lines, strategically develop marketing strategies based on an individual's shopping habits and to create predictive models of what products and individual will likely need in the future [40]. Insurance companies use big data and analytics to set insurance prices based on your demographic information, and medical analytics track the spread of disease to help target intervention [38].

With the increasing adoption of online education, the increasing use of mobile devices in education, the recent advent of learning data standards such as XAPI and Caliper, and the recent push for learning systems interoperability, there is the potential to capture 'Big Educational Data' and apply analytics to learning data in a learning ecosystem. Remaining questions include how to best apply these analytics strategies in education, and which data items should be captured? Different types of analytics for the purposes of education are summarized below. The scope of data and data ethics and security are then considered. 


\subsection{Business analytics}

In a learning ecosystem context, business analytics give decision makers access to indicators and dashboards outlining how the learning ecosystem is performing. The identification and use of learner patterns and behaviours can be used to inform future design strategies [40]. This type of analytics is most useful for individuals who govern the learning ecosystem.

\subsection{Academic analytics}

Academic analytics offer leaders and individual learner's data detailing learner performance data and knowledge flow [41]. Academic analytics may include a top down view of learner knowledge and skills ecosystem-wide, broken down into different demographics (with comparisons between), or narrowed down to a specific course or cohort. At the individual learner level, academic analytics may include data organized into semantic ePortfolios (element four of the LEF 2.0). This form of analytics is most useful for governance members, system administrators, instructors, and learners.

\subsection{Learning analytics}

Learning analytics has been defined as the "measurement, collection, analysis and reporting of data about learners and their contexts, for purposes of understanding and optimizing learning and the environments in which it occurs" [42]. Learning analytics can include interpreting learning data against pedagogical intent, as the authors of Ref. [43] outline with their framework of checkpoint and process analytics. Learning data can be captured in the form of click data, learner experience data, and learner performance data. For online discussions, discourse data can be analyzed through social network analysis and lexical analysis - see for example Ref. [44]. Learning Analytics can also include a training evaluation framework such as the one discussed in Ref. [45], which includes data measuring results, behaviour, learning, and reaction. This form of analytics is most useful for course instructors, instructional designers, and course developers.

\subsection{Predictive analytics}

Predictive analytics can be described as an "area of statistical analysis that deals with extracting information using various technologies to uncover relationships and patterns within large volumes of data that can be used to predict future behaviour and events" [39, p. 9]. It is often used to develop early warning systems, and adaptive knowledge systems (see element seven of the LEF 2.0). This type of information is useful for governance members, system administrators, instructors, and learners. 


\subsection{Scope of data}

"What data should I capture?" is a key challenge when considering the implementation of analytics. In particular, it is important to collect data that is meaningful relative to your analytic goals, rather than simply capturing 'everything in case it is needed'. Ref. [46] provides a set of six "W" questions, shown in Table 3, to be considered when developing analytic approaches.

Table 3. Questions to consider when planning to capture learning data

\begin{tabular}{|l|l|}
\hline \multicolumn{1}{|c|}{ Element } & \multicolumn{1}{c|}{ Questions } \\
\hline Epistemology & $\begin{array}{l}\text { What are we measuring? } \\
\text { How are we measuring? }\end{array}$ \\
\hline Pedagogy & $\begin{array}{l}\text { Why is this knowledge important to us? } \\
\text { Who is the assessment/analytic for? }\end{array}$ \\
\hline Assessment & $\begin{array}{l}\text { Where does the assessment happen? } \\
\text { When does the assessment and feedback occur? }\end{array}$ \\
\hline
\end{tabular}

With similar goals in mind, the authors of Ref. [47], adapted the Rapid Outcome Mapping Approach (ROMA) for the learning analytics context developed by Ref. [48]. This model includes seven steps:

1) Define a clear set of overarching policy objectives

2) Map the context

3) Identify the key stakeholders

4) Identify learning analytics purpose

5) Develop a strategy

6) Analyze capacity; develop human resources

7) Develop a monitoring and learning system (evaluation) [47]

Building on ROMA, the SHEILA project provides for a validated framework that includes:

1) Map the political context

2) Identify key stakeholders

3) Identify desired behaviour changes

4) Develop an engagement strategy

5) Analyze internal capacity to effect change

6) Establish monitoring and learning frameworks [49].

The SHEILA project includes a website which expands on this and provides for an online tool to create your own framework. This website can be found here http://sheilaproject.eu/sheila-framework/create-your-framework/overview/. 


\subsection{Data ethics and security}

Invasive privacy policies, selling of personal data, and the increasing number of data breaches speak to the need for a commitment to data ethics and security. Simply typing your email address into https://haveibeenpwned.com shows the scale of security breaches from a multitude of websites and organizations, with billions of pieces of personal information stolen. Recent privacy scandals from Cambridge Analytica and Facebook, and breaches from Equifax and Chase credit card have revealed public distrust and anxiety about how organizations are using and securing data. With these growing concerns, it is vital that data ethics and security be a top priority. According to Ref. [36], the main ethical and privacy issues in learning analytics include "the collection and aggregation of data, informed consent, de-identification of data, transparency, data security, interpretation of data, and classification and management" (p.6). A few organizations have developed frameworks which are of use to data ethics and security in a learning ecosystem. Two of these frameworks are described below.

OECD privacy framework: The Organization for Economic Co-operation and Development (OECD) developed the first internationally agreed upon principles of data privacy. This privacy framework is shown in Table 4, as summarized by Ref. [36].

Table 4. OECD privacy framework

\begin{tabular}{|c|c|}
\hline Element & Description \\
\hline Collection limitations & $\begin{array}{l}\text { "There should be limits to the collection of personal data. Data should be } \\
\text { obtained by lawful and fair means and, where appropriate, with the } \\
\text { knowledge or consent of the data subject." }\end{array}$ \\
\hline Data quality & $\begin{array}{l}\text { "Personal data should be relevant to the purposes for which they are to be } \\
\text { used, and to the extent necessary for those purposes. Data should be accurate, } \\
\text { complete and kept up-to-date." }\end{array}$ \\
\hline Purpose specification & $\begin{array}{l}\text { "The purposes for which personal data are collected should be specified not } \\
\text { later than at the time of data collection. Subsequent use should be limited to } \\
\text { the fulfillment of those purposes or compatible purposes." }\end{array}$ \\
\hline Use limitation & $\begin{array}{l}\text { "Personal data should not be disclosed, made available or used for purposes } \\
\text { other than specified - except with the consent of the data subject or by the } \\
\text { authority of the law." }\end{array}$ \\
\hline Security safeguards & $\begin{array}{l}\text { "Personal data should be protected by reasonable security safeguards against } \\
\text { loss or unauthorized access, destruction, use, modification, or disclosure." }\end{array}$ \\
\hline Openness & $\begin{array}{l}\text { "There should be a general policy of openness about developments, practices } \\
\text { and policies with respect to personal data. Information on the existence and } \\
\text { nature of personal data, purpose of their use, and the identity and location of } \\
\text { the data controller should be available." }\end{array}$ \\
\hline Individual participation & $\begin{array}{l}\text { "Individuals should have the right to obtain confirmation of whether or not } \\
\text { data relating to them is held and to have communicated to them the data, to be } \\
\text { given reasons if a request is denied, and to challenge data relating to them and }\end{array}$ \\
\hline
\end{tabular}




\begin{tabular}{|l|l|}
\hline & to have the data erased, rectified, completed or amended." \\
\hline Accountability & $\begin{array}{l}\text { "The data controller should be accountable for complying with measures } \\
\text { which give effect to the above principles." }\end{array}$ \\
\hline
\end{tabular}

JISC's code of practice for learning analytics: JISC, an organization providing digital solutions for education and research in the United Kingdom, sets out eight guidelines in what they call a "Code of practice for learning analytics". The guidelines, as summarized by Ref. [36] are displayed in Table 5.

Table 5. JISC's code of practice for learning analytics

\begin{tabular}{|c|c|}
\hline Element & Description \\
\hline Responsibility & $\begin{array}{l}\text { "Institutions must decide who has overall responsibility for the legal, ethical and } \\
\text { effective use of learning analytics." }\end{array}$ \\
\hline $\begin{array}{l}\text { Transparency } \\
\text { and consent }\end{array}$ & $\begin{array}{l}\text { "Institutions will define the objectives for the use of learning analytics, what data is } \\
\text { necessary to achieve these objectives, and what is out of scope." }\end{array}$ \\
\hline Privacy & $\begin{array}{l}\text { "Access to student data and analytics should be restricted to those identified by the } \\
\text { institution as having a legitimate need to view them." }\end{array}$ \\
\hline Validity & $\begin{array}{l}\text { "It is vital that institutions monitor the quality, robustness and validity of their data } \\
\text { and analytics processes in order to develop and maintain confidence in learning } \\
\text { analytics and ensure it is used to the benefit of students." }\end{array}$ \\
\hline Access & $\begin{array}{l}\text { "Students should be able to access all learning analytics performed on their data in } \\
\text { meaningful, accessible formats, and to obtain copies of this data in a portable digital } \\
\text { format." }\end{array}$ \\
\hline $\begin{array}{l}\text { Enabling } \\
\text { positive inter- } \\
\text { ventions }\end{array}$ & $\begin{array}{l}\text { "Institutions should specify under which circumstances they believe they should } \\
\text { intervene when analytics suggests that a student could benefit from additional sup- } \\
\text { port." }\end{array}$ \\
\hline $\begin{array}{l}\text { Minimizing } \\
\text { adverse impacts }\end{array}$ & $\begin{array}{l}\text { "Institutions recognize that analytics can never give a complete picture of an individ- } \\
\text { ual's learning and may sometimes ignore personal circumstances. Institutions will } \\
\text { take steps to ensure that trends, norms, categorization or any labeling of students do } \\
\text { not bias staff, student or institutional perceptions and behaviours towards them, } \\
\text { reinforce discriminatory attitudes or increase social power differentials." }\end{array}$ \\
\hline $\begin{array}{l}\text { Stewardship of } \\
\text { data }\end{array}$ & $\begin{array}{l}\text { "Data for learning analytics will comply with existing institutional data policies and } \\
\text { the DPA (Data Protection Act)" }\end{array}$ \\
\hline
\end{tabular}

To maintain the trust of learners engaging with the learning ecosystem, a dedication to data ethics and privacy is a must. Providing the learner control and ownership over their data, for example, allowing them to choose what systems or organizations can access their data, may be advisable. Policies and guidelines, such as those described in Ref. [37], must be established. 


\section{$7 \quad$ Semantic Portfolios}

A growing number of organizations are implementing ePortfolios as a tool to support student learning and assessment [50], because they afford learners the opportunity to provide evidence of their learning $[6,51]$. Within a learning ecosystem, a semantic ePortfolio can show a learner's learning progression throughout their entire career. It can be designed to show where more support is needed or show suggestions for next steps based on an identified career path.

There are two primary ways information can be added to semantic ePortfolios in the LEF 2.0. First is the more traditional route, where learners can add work they want to display, in a variety of formats, including audio, images, videos, and text [52]. The second is through use of the wealth of learning data available as part of the learning ecosystems data architecture. This data is especially useful if learning content and activities are designed around a competency-based system. As learners engage with content, activities, evaluations, assessments, etc., a record of this engagement and learner performance is captured for each competency and is added to the ePortfolio. An opportunity exists to gamify this data [6]. Learners could work towards leveling up in the identified competencies. Content, evaluations, assessments, etc. could award experience points towards the competencies. New learning content and activities could be unlocked as a learner level up. Gamified or not, the automatic collection of learning data into the learners ePortfolio allows the learner to see their progress over time and gives them an avenue to provide evidence of their knowledge and skill development.

\section{$8 \quad$ Intrinsic and Extrinsic Motivators}

Keeping learners motivated to learn can be a challenge. Within a learning ecosystem, the challenge is even greater as learners must continue to be motivated throughout their career. Ref. [53] focused on the elements that make games fun and educational. Through their work the authors developed a taxonomy of intrinsic and extrinsic motivations that include:

1) Challenge

2) Curiosity

3) Control

4) Cooperation

5) Competition

6) Recognition

More recently the authors of Ref. [54] utilized this taxonomy, described below, in the mobile learning landscape. They offer examples to illustrate how each motivator could be utilized in a learning ecosystem both at the individual course level, and ecosystem-wide. 


\subsection{Intrinsic motivators}

The ultimate goal is "to develop learners who are self-directed and self-motivated" [54, p. 85]. To assist in achieving this goal, Ref. [53] proposes three critical intrinsic motivators.

Challenge: Keep learners within their zone of proximal development [24]. Ref. [2] speaks to a need to balance challenge with the needs and abilities of the individual student. An adaptive knowledge system (part of element seven of the LEF 2.0) could be employed, adapting the difficulty of content automatically based on the needs of the learner as derived from the learning data. Ref. [53] suggests additional methods for maintaining an appropriate challenge level, including creation of different levels of instruction that students can choose from, introducing time constraints, and providing incomplete information so that the learner must engage in their own process of inquiry. Aside from different levels of content difficulty, challenges from an ecosystem-wide level could be put forth for learners to complete. Similar to achievements in video games, these challenges could include time-based completions, beating personal high scores, achieving competency levels, etc. It is evident that such challenges might also effectively leverage extrinsic motivators such as cooperation, competition, and recognition (see section 8.2, below).

Curiosity: Stimulate learner curiosity through careful learning design. Curiosity is divided into two broad categories: sensory curiosity and cognitive curiosity [53]. Sensory curiosity is stimulated by effecting changes in the learning environment depending on learner actions. This could include changes in light, sound, or other sensory stimuli [54]. Sound effects, music, animations, haptic feedback, etc. can be used as learners perform actions, such as clicking a button, getting an answer correct, completing content, leveling up a competency, earning an achievement, etc. Cognitive curiosity is spurred when a learner discovers their knowledge or skills are incomplete, causing them to want to explore and learn new information or skills. This may be achieved by offering learners appropriate challenges [53]. At the ecosystem level, competency level pathways could be displayed to the learner allowing them to see content and activities that may contain new information that they have yet to unlock. Additionally, “did you know" notifications can 'nudge' learners to engage with content in the ecosystem.

Control: Provide the user control over their learning experience by offering choices, letting them set goals, letting them control the pace of learning, and automatically curating content based on their identified areas of interest [53, 54, 2]. The learning experience platform (LXP) Degreed (https://degreed.com/), asks users to identify areas of knowledge and skill development interests when they first create their account (though these can be edited later). Degreed then curates content for the learner based on these preferences into a Facebook-like newsfeed. This control measure allows learners to customize their learning experience based on what they want to learn rather than what an organization wants them to learn. 


\subsection{Extrinsic motivators}

Ref. [53] suggests three forms of extrinsic motivation that can also support selfdirected learning skills.

Cooperation: Create a learner-centered, socially interactive environment allowing users to learn at their own pace, learn and collaborate with other users, and allow users to work toward common goals or achievements [54]. Employing methods of social networks (element six of the LEF 2.0) and allowing learners to work towards common goals can support cooperation. For example, create course-based or ecosystem-wide challenges that can be collaboratively worked towards by all learners.

Competition: Promote healthy competition between individuals or groups through ecosystem-wide and/or course-based competitions. This could be achieved through time-based competitions, achieving levels, achieve a certain number of experience points, etc. can be utilized to create competitions amongst individuals or groups.

Recognition: Provide public recognition of users' accomplishments through leaderboards, achievements, levels, points, and other forms of recognition [54]. Highlight learner accomplishments within a social network-like structure or through email blasts, such as monthly newsletters, to provide recognition.

\section{$9 \quad$ Social Learning and Engagement}

Social learning and engagement methods allow for connections to be made between the biotic units of the learning ecosystem. Ref. [4] highlights the need for collaboration in their NGDLE, arguing that an important goal when considering the design of a learning environment is including resources, tools and support for collaboration. Ref. [2] also includes discussion, and collaboration tools as part of their learning ecosystem framework. While the importance of learning in a social space and as part of a community has been established in the literature and in the works of Piaget and Vygotsky [55, 56, 57, 58, 59, 60, 61], a limitation of many learning systems has been the implementation of social tools only within a course space [4]. This limits social learning and engagements to specific groups at specific times and does not afford the option to continue the discussions after a course has completed.

With the emergence of social networks, it is argued these platforms have the potential to enhance online learning and engagement [62]. Platforms such as Facebook, LinkedIn, Twitter, Instagram, and YouTube offer individuals a space to establish and maintain relationships, follow other people, express themselves, discuss topics, and share pieces of their lives with others [62, 63]. Learning Experience Platforms (LXP) have come into the scene recently to take advantage of the affordances of social networks. For example, as described previously, the LXP Degreed curates content from the Internet based on a learner's declared interests and presents content to the learner in a Facebook-like newsfeed. Learners across the platform can engage with each other about this content in a similar fashion to Facebook discussions. LMSs too have taken to integrating elements of social networks into their systems. In the popular LMS SABA (https://www.saba.com) for example, learners can post their own content, follow other learners on the platform, and have discussions outside of course spaces. 


\section{Personalization}

Personalization of the learning ecosystem is a critical factor in shaping the user experience of the learning ecosystem and is dependent on interoperability [4]. According to Ref. [4], personalization consists of two aspects:

1) Personalization of the learning environment

2) Adaptive learning

\subsection{Personalization of the learning environment}

Personalization allows all users of a learning ecosystem to shape elements of the ecosystem to fit their specific needs and local context. Allowing learners, instructors, and organizations to be the "architects of their learning environment" (p. 5) is powerful [4]. From a learner's perspective, this may include choosing what device to use when engaging with content, choosing what content to engage with, choosing which features are available to them, choosing what data to share with the learning ecosystem, and customizing elements of the user interface. From an instructor's perspective, this may include choosing what tools are available in their course space, choosing a learning platform and delivery method (e.g. traditional eLearning format vs pushed content to a learner's email), and customizing the user interface of their course space. From an organizations perspective, this may include choosing what learning systems their data and systems connect with (especially if the learning ecosystem spans across multiple organizations), customizing access settings so they can administrate the system the way they need to, and customizing elements of the user interface to reflect the brand of the organization.

\subsection{Adaptive learning}

While adaptive learning is not a new concept, advancements in technology have created a resurgence of the idea [64]. Adaptive learning utilizes the ecology of the learning ecosystem, putting the data to work to provide a personalized experience by suggesting learning content and activities to meet the specific needs of the learner [38]. Learner performance and engagement data is analyzed and mapped against a competency framework that describes expected knowledge, skills, behaviours, and attitudes [3]. The system then alters the learner's pathway, suggests learning content, activities, resources, and coaching to remediate or advance the learner [3, 4, 64]. A high-quality technology and data architecture is imperative for creating a learning ecosystem that is adaptive and responsive to the immediate needs of the learner $[6,15$, 4]. It is important to note however, that while adaptive learning has promise and has generated some excitement, it is not uncontroversial. Seen by some as a "digital snake oil", adaptive learning projects such as Arizona State Universities "Knewton", which saw an investment of $\$ 180$ million, was a complete failure [65]. While this is not a call to abandon adaptive learning, it is an important note to be critical about the claims of adaptive learning system, to recognize adaptive learning as simply another availa- 
ble design feature we may adopt, and to ensure data strategies and usage are supported by the literature and that they follow well established data ethics and security policies.

\section{Discussion and Conclusion}

The notion that an LMS is sufficient for supporting employee learning and development throughout their career is no longer credible. LMSs have so far failed to keep pace with the affordances of contemporary technologies, suffer from poor interoperability, collect poor learning data, and typically lack any capacity for personalization. Addressing these limitations requires thinking about learning environments from a different perspective: the ecological and holistic approach of a learning ecosystem. learning ecosystem. The proposed LEF 2.0 described in this paper combines existing literature to create a framework that considers the entire ecology of a learning ecosystem and is offered as a guide to mature existing organizational learning ecosystems.

The LEF 2.0 should be worked towards in stages: Elements 1-3 should be the initial focus. The importance of the technology and data architecture cannot be understated. It is the foundation that all functions of the learning ecosystem rely on, and its structure determines the future scalability of the ecosystem, allowing it to grow with the needs of the learner and organization. Establishing governance will position the learning ecosystem at a strategic level, increase organizational buy-in, and guide the growth and sustainability of the learning ecosystem. Gathering and using analytics in the initial stages will provide insights into how the learning ecosystem is being used, will provide education developers with useful data for improving current and future courses and activities, will provide governance with data to base strategic decisions on, and will inform next steps for further implementation of the LEF 2.0. In the initial stages of maturing the learning ecosystem, it is suggested to start small, capture targeted data to avoid becoming overwhelmed.

Future directions for research should focus on each individual element of the LEF 2.0, a dive deeper into the literature to uncover best practices in design and implementation, and to apply these elements in real world settings. While there is a wealth of literature about each element, how the elements best support the ecology of a learning ecosystem should be explored further. Additionally, an examination of how a learning ecosystem can best support organizational needs should be conducted.

\section{Acknowledgement}

The authors would like to thank the Ontario Centres for Learning, Research and Innovation in Long-Term Care (CLRI) as their work on education in the Ontario Long-Term Care Sector inspired the investigation into the topic of this paper. 


\section{References}

[1] LinkedIn Learning (2018). 2018 workplace learning report: The rise and responsibility of talent development in training systems and tools in the new labor market. Retrieved from: https://learning.linkedin.com

[2] Wilkinson, D. L. (2002). The intersection of learning architecture and instructional design in e-learning, NATO Education Training Exercise and Evaluation Conference (pp. 213221). ETEE.

[3] Smith, B., Gallagher, P. S., Shatz, S., \& Vogel-Walcutt, J. (2018). Total learning architecture: moving into the future. In Proceedings of the Interservice/Industry Training, Simulation, and Education Conference (I/ITSEC).

[4] Brown, M., Dehoney, J., \& Millichap, N. (2015). The next generation digital learning environment. A Report on Research. ELI Paper. Louisville, CO: Educause April.

[5] Chang, V., \& Guetl, C. (2007, February). E-learning ecosystem (ELES) - a holistic approach for the development of more effective learning environment for small-and-medium sized enterprises (SMEs). IEEE International Conference on Digital Ecosystem and Technologies (pp. 420-425). IEEE. https://doi.org/10.1109/dest.2007.372010

[6] García-Peñalvo, F. J., Hernández-García, Á., Conde, M. Á., Fidalgo-Blanco, Á., SeinEchaluce, M. L., Alier, M., Llorens-Largo, F., \& Iglesias-Pradas, S. (2015, October). Learning services-based technological ecosystems. In Proceedings of the 3rd International Conference on Technological Ecosystems for Enhancing Multiculturality (pp. 467-472). ACM. https://doi.org/10.1145/2808580.2808650

[7] García-Peñalvo, F. J., Johnson, M., Alves, G. R., Minović, M., \& Conde-González, M. Á. (2014). Informal learning recognition through a cloud ecosystem. Future Generation Computer Systems, 32, 282-294. https://doi.org/10.1016/j.future.2013.08.004

[8] Chang, V., \& Uden, L. (2008). Governance for e-learning ecosystem, IEEE International Conference on Digital Ecosystem and Technologies (pp. 340-345). IEEE. https://doi.org/ 10.1109/dest.2008.4635164

[9] Gütl, C., \& Chang, V. (2008). Ecosystem-based theoretical models for learning in environments of the 21 st century. International Journal of Emerging Technologies in Learning (iJET), 3(2008), 50-60. https://doi.org/10.3991/ijet.v3i1.742

[10] Folsom-Kovarik, J. T. \& Raybourn, E. M. (2016). Total learning architecture (TLA) enables next-generation learning via meta-adaption, Interservice/Industry Training, Simulation, and Education Conference. Arlington, VA: NTSA

[11] Encyclopaedia Britannica. (n.d.). Ecosystem. Retrieved from https://www.britannica.com /science/ecosystem

[12] Eudy, R. (2018, July 18). What is a learning ecosystem? And how does it support corporate strategy? [Web blog post]. Retrieved from https://www.ej4.com/blog/what-is-a-learn ing-ecosystem

[13] Aparicio, M., Bacao, F., \& Oliveira, T. (2016). An e-learning theoretical framework. Education Technology \& Society, 19 (1), 292-307.

[14] Giannakos, M. N., Krogstie, J., \& Aalberg, T. (2016). Toward a learning ecosystem to support flipped classroom: A conceptual framework and early results. In Y. Li, M. Chang, M. Kravcik, E. Popescum, R. Huang, Kinshuk, \& N.S. Chen (Eds.), State-of-the-Art and future directions of smart learning (pp. 105-114). Singapore: Springer. https://doi.org/10. 1007/978-981-287-868-7_12

[15] Blake-Plock S. \& Hoyt, W. (2018). Mission control for learning and performance [Whitepaper]. Retrieved October 2, 2018 from https://www.yetanalytics.com/white paper-missioncontrol 
[16] Uden, L., Wangsa, I. T., \& Damiani, E. (2007, February). The future of E-learning: Elearning ecosystem. In 2007 Inaugural IEEE-IES Digital EcoSystems and Technologies Conference (pp. 113-117). IEEE. https://doi.org/10.1109/dest.2007.371955

[17] Abel, R. 7 things you should know about learning tools interoperability. Retrieved from https://library.educause.edu/resources/2013/8/7-things-youshould-know-about -lti https://doi.org/10.1016/b978-0-12-809485-3.00001-6

[18] IMS Global Learning Consortium. (n.d.). LTI v1.3 and LTI Advantage. Retrieved from https://www.imsglobal.org/activity/learning-tools-interoperability

[19] Neville, K. J., \& Folsom-Kovarik, J. T. (2018). Recommendation across many learning systems to optimize teaching and training. In International Conference on Applied Human Factors and Ergonomics (pp. 212-221). New York: Springer. https://doi.org/10.1007/978-3 -319-94782-2_21

[20] IMS Global Learning Consortium. (n.d.). Initial xAPI/Caliper Comparison. Retrieved from https://www.imsglobal.org/initial-xapicaliper-comparison

[21] University of Toronto. (n.d.). WLD-FLXD - Fundamentals of learning experience design. Retrieved from https://cpl.oise.utoronto.ca/search/publicCourseSearchDetails. do? method=load\&courseId $=25897$

[22] Hokanson B. (2015) Introduction. In: Hokanson B., Clinton G., Tracey M. (eds) The Design of Learning Experience (pp.1-3). New York: Springer.

[23] Baumann, B. (2018). The modern learner and learning experience design. Retrieved from https://trainingindustry.com/articles/content-development/the-modern-learnerand-learning-experience-design/

[24] Vygotsky, L. S. (1978). Mind in society (M. Cole, V. John-Steiner, S. Scribner, \& E. Souberman, Eds.).

[25] Macfadyen, L. P., \& Dawson, S. (2012). Numbers Are Not Enough. Why e-learning analytics failed to inform an institutional strategic plan. Educational Technology \& Society, 15 (3), 149-163.

[26] Chatti, M. A., Dyckhoff, A. L., Schroeder, U., \& Thüs, H. (2013). A reference model for learning analytics. International Journal of Technology Enhanced Learning, 4(5-6), 318331. https://doi.org/10.1504/ijtel.2012.051815

[27] Ouf, S., Nasr, M., \& Helmy, Y. (2010, December). An enhanced e-learning ecosystem based on an integration between cloud computing and Web2. 0. In The 10th IEEE International Symposium on Signal Processing and Information Technology (pp. 48-55). IEEE. https://doi.org/10.1109/isspit.2010.5711721

[28] Amazon Web Services. (n.d.). What is a data lake? Store all your data in one centralized repository at any scale. Retrieved from https://aws.amazon.com/big-data/datalakes-andanalytics/what-is-a-data-lake/

[29] Griffiths, D. \& Hoel, T. (2016). Comparing xAPI and Caliper. Retrieved from Learning Analytics Community Exchange (LACE) website: http://www.laceproject.eu/learninganalytics-review/files/2016/08/LACE-review07 xapi-caliper.pdf

[30] Rustici Software. (n.d.). xAPI solved and explained. Retrieved from https://xapi.com/

[31] IMS Global Learning Consortium. (n.d.). Caliper Analytics. Retrieved from https://www. imsglobal.org/activity/caliper

[32] Amazon Web Services. (n.d.). Amazon Kinesis. Retrieved from https://aws.amazon. $\underline{\mathrm{com} / \mathrm{kinesis/}}$

[33] Haftor, D. \& Kajtazi, M. (2009). What is information logistics? An explorative study of the research frontiers of information logistics. Retrieved from http://lnu.diva-portal.org/ smash/get/diva2:344139/FULLTEXT01 
[34] Alaeddini, M., \& Kardan, A. A. (2010, June). E-learning governance-Towards an applicable framework. In 2010 2nd International Conference on Education Technology and Computer (Vol. 3, pp. V3-529). IEEE. https://doi.org/10.1109/icetc.2010.5529486

[35] Frank, J. R., Snell, L. S., Cate, O. T., Holmboe, E. S., Carraccio, C., Swing, S. R., Harris, P. D., Glasgow, N.J., Campbell, C., Dath, D., Harden, R. M., Iobst, W. F., Long, D.M., Mungroo, R., Richardson, D. L., Sherbino, J., Silver, I., Taber, S. A., Talbot, M., \& Harris, K, A. (2010). Competency-based medical education: theory to practice. Medical teacher, 32(8), 638-645. https://doi.org/10.3109/0142159x.2010.501190

[36] Griffiths, D., Drachsler, H., Kickmeier-Rust, M., Steiner, C., Hoel, T., \& Greller, W. (2016). Is privacy a show-stopper for learning analytics? A review of current issues and solutions. Learning Analytics Review, 6.

[37] The Open University. (2014). Policy on ethical use of student data for learning analytics. Retrieved from https://help.open.ac.uk/documents/policies/ethical-use-of-stu dent-data

[38] Sclater, N. (2017). Learning analytics explained. New York, NY: Routledge.

[39] van Barneveld, A., Arnold, K. E., \& Campbell, J. P. (2012). Analytics in higher education: Establishing a common language. EDUCAUSE learning initiative, 1(1), 1-11.

[40] Duhigg, C. (2012). How companies learn your secrets. Retrieved from https://www.ny times.com/2012/02/19/magazine/shopping-habits.html?pagewanted=all

[41] Long, P., \& Siemens, G. (2011). Penetrating the Fog: Analytics in Learning and Education. EDUCAUSE review, 46(5), 30.

[42] LAK. (2011). 1st international conference on learning analytics and knowledge 2011. Retrieved from https://tekri.athabascau.ca/analytics/

[43] Lockyer, L., Heathcote, E., \& Dawson, S. (2013). Informing pedagogical action: Aligning learning analytics with learning design. American Behavioral Scientist, 57(10), 1439-1459. https://doi.org/10.1177/0002764213479367

[44] Chen, B., Chang, Y. H., Ouyang, F., \& Zhou, W. (2018). Fostering student engagement in online discussion through social learning analytics. The Internet and Higher Education, 37, 21-30. https://doi.org/10.1016/j.iheduc.2017.12.002

[45] Kirkpatrick J. \& Kirkpatrick W. (2016). Kirkpatrick's four levels of training evaluation. Alexandria, VA: ATD press.

[46] Knight, S. \& Shum, S.B. (2017). Chapter 1: Theory and Learning Analytics. In Lang, C., Siemens, G., Wise, A., \& Gasevic, D. (Eds.), Handbook of learning analytics (pp. 17-22). https://doi.org/10.18608/hla17.001

[47] Ferguson, R., Macfadyen, L., Clow, D., Tynan, B., Alexander, S., \& Dawson, S. (2014). Setting learning analytics in context: Overcoming the barriers to large-scale adoption. Journal of Learning Analytics, 1(3), 120-144. https://doi.org/10.18608/jla.2014.13.7

[48] Young, J., \& Mendizabal, E. (2009). Helping researchers become policy entrepreneurs. How to develop engagement strategies for evidence-based policy-making. (Briefing $\mathrm{Pa}$ per). Retrieved from https://www.odi.org/resources/docs/1730.pdf

[49] SHEILA. (n.d.). Sheila overview. Retrieved from http://sheilaproject.eu/sheila-framework /create-your-framework/overview/

[50] Luchoomun, D., McLuckie, J., \& van Wesel, M. (2010). Collaborative e-learning: ePortfolios for assessment, teaching and learning. Electronic Journal of e-Learning, 8(1), 21-30.

[51] Romero, L., Gutierrez, M., \& Caliusco, M. L. (2017). Semantic modeling of portfolio assessment in e-learning environment. Advances in Science, Technology and Engineering Systems, 2(1), 149-156. https://doi.org/10.25046/aj020117 
[52] Koraneekij, P., \& Khlaisang, J. (2015). Development of learning outcome based eportfolio model emphasizing on cognitive skills in pedagogical blended e-learning environment for undergraduate students at faculty of education, Chulalongkorn University. Procedia-Social and Behavioral Sciences, 174, 805-813. https://doi.org/10.1016/j.sbspro. 2015.01.664

[53] Malone, T.W., \& Lepper, M. R. (1987). Making learning fun: A taxonomy of intrinsic motivations for learning. In R. E.Snow \& M. J. Farr (Eds.), Aptitude, learning, and instruction: III. Conative and affective process analyses (pp. 223-253). Hillsdale, NJ: Erlbaum.

[54] Ciampa, K. (2013). Learning in a mobile age: an investigation of student motivation. Journal of Computer Assisted Learning, 30, 82-96. https://doi.org/10.1111/jcal.12036

[55] John-Steiner, V., \& Mahn, H. (1996). Sociocultural approaches to learning and development: A Vygotskian framework. Educational psychologist, 31(3-4), 191-206. https://doi. org/10.1207/s15326985ep3103\&4_4

[56] Bandura, A., \& Walters, R. H. (1977). Social learning theory (Vol. 1). Englewood Cliffs, NJ: Prentice-hall.

[57] Good, R., Mellon, E. K., \& Kromhout, R. A. (1978). The work of Jean Piaget. Journal of Chemical Education, 55(11), 688. https://doi.org/10.1021/ed055p688

[58] Palincsar, A. S. (1998). Social constructivist perspectives on teaching and learning. Annual review of psychology, 49(1), 345-375. https://doi.org/10.1146/annurev.psych.49.1.345

[59] Packer, M. J., \& Goicoechea, J. (2000). Sociocultural and constructivist theories of learning: Ontology, not just epistemology. Educational psychologist, 35(4), 227-241. https:// doi.org/10.1207/s15326985ep3504_02

[60] Liu, S. H. J., \& Lan, Y. J. (2016). Social constructivist approach to web-based EFL learning: Collaboration, motivation, and perception on the use of Google Docs. Journal of Educational Technology \& Society, 19(1), 171-186.

[61] Glăveanu, V. P., Ness, I. J., Wasson, B., \& Lubart, T. (2019). Sociocultural Perspectives on Creativity, Learning, and Technology. In C. A. Mullen (Ed.), Creativity Under Duress in Education? (pp. 63-82). Springer, Cham. https://doi.org/10.1007/978-3-319-90272-2_4

[62] Greenhow, C., \& Lewin, C. (2016). Social media and education: Reconceptualizing the boundaries of formal and informal learning. Learning, media and technology, 41(1), 6-30. https://doi.org/10.1080/17439884.2015.1064954

[63] Yu, A. Y., Tian, S. W., Vogel, D., \& Kwok, R. C. W. (2010). Can learning be virtually boosted? An investigation of online social networking impacts. Computers \& Education, 55(4), 1494-1503. https://doi.org/10.1016/j.compedu.2010.06.015

[64] Dziuban, C., Howlin, C., Moskal, P., Johnson, C., Parker, L., \& Campbell, M. (2018). Adaptive learning: A stabilizing influence across disciplines and universities. Online Learning, 22(3), 7-39. https://doi.org/10.24059/olj.v22i3.1465

[65] Warner, J. (2019). Knewton is gone. The larger threat remains. [Web blog post]. Retrieved from https://www.insidehighered.com/blogs/just-visiting/knewton-gone-la rger-threat-remains\#.XNOoR2AnVQc.link

\section{Authors}

William Derek Redmond is a graduate of the Master of Educational Technology Program from The University of British Columbia. He works as an Instructional Designer \& Educational Technologies Specialist at PointClickCare. He is a Director and Executive Committee Member for the Canadian eLearning Conference. It is important 
to note that his paper was written in his personal capacity and any opinions expressed herein are the author's own and do not reflect the views of PointClickCare.

Leah P. Macfadyen is Associate Director of the UBC Master of Educational Technology program, and a faculty member in UBC's Department of Language and Literacy Education. She makes use of learning analytics to inform course and curriculum review, and to discover meaningful patterns that can inform improvements in learning design, teaching, and learning. She also thinks and writes about the limits of 'big data', the challenge of data literacy, and the ethical and social implications of this work.

Article submitted 2019-10-17. Resubmitted 2019-12-10. Final acceptance 2019-12-13. Final version published as submitted by the authors. 